\title{
Application of case discussions to improve anatomy learning in Syria
}

Mohammad Ayman Sabbagh

Department of Anatomy, Al Baath University, Hama, Syria

\begin{tabular}{|c|}
\hline Access this article online \\
\hline Website: www.avicennajmed.com \\
\hline DOI: 10.4103/2231-0770.120499 \\
\hline Quick Response Code: \\
$\square$ \\
\hline
\end{tabular}

\section{ABSTRACT}

AIMS: Designing a new approach for learning gross anatomy to improve students' motivation to study anatomy and to enable them to learn independently through case discussion. MATERIALS AND METHODS: The study included newly registered students in the first academic year. The total number of students was 165 , who were divided by alphabetical order into 15 groups of 11 students. Each group was led by one faculty member and each faculty member lead 3 groups. Each group met twice a week for 2 weeks to discuss one case related to the upper limb anatomy. Students took pre- and posttests and completed an opinion questionnaire about the case discussions. RESULTS: The pretest score shows that $20 \%$ of the students received grades of $60 \%$ or above and that $80 \%$ received grades less than $60 \%$. The posttest showed that $45 \%$ of the students received grades of $60 \%$ or above and that $55 \%$ received grades less than $60 \%$. There was a significant difference between the pre- and posttest for grades $<60 \%(P=0.0000)$ and less significant for grades $>60 \%(P=0.0023)$. In addition, $17 \%$ of students achieved the same results (less than $60 \%$ ) in both the pre- and posttests. The questionnaire revealed that all students stated that the discussion method was useful in their learning process, helped them to increase their motivation to study anatomy (85\%), know the usefulness of studying anatomy $(84 \%)$, and understand the problems $(91 \%)$. CONCLUSIONS: The implementation of the case discussion in teaching anatomy can increase the students' understanding and motivate them to learn.

Key words: Anatomy learning, anatomy teaching, case discussion, medical students, problem-assisted learning, problem-based learning

\section{INTRODUCTION}

Gross anatomy has become "integrated anatomy". The traditional dissection labs and chalkboard illustrations are giving way to robotic simulators, plasticized specimens, and computer imaging. ${ }^{[1]}$ Some medical schools decided to create an integrated basic science program where students will learn anatomy, physiology, and histology in one course with the theme of "Human Structure and Function", which is taught by both anatomists and clinicians. ${ }^{[2-15]}$

Students at Al-Baath University in Syria join medical school directly from high school. The medical curriculum is a traditional teaching model designed for a large group of students. Gross anatomy is presented in the $1^{\text {st }}$ year of the curriculum and consists of didactic lectures and hands-on dissection labs. The teaching style is mostly teacher-centered, where knowledge is transmitted from professor to students. Therefore, the students passively receive information, which is usually delivered in Arabic. Since the gross anatomy course requires much memorization and is limited to didactic coursework, the students may fail to appreciate the relevance between gross anatomy and other subjects. Consequently, during their clinical attachment years, it is difficult for them to implement their anatomical knowledge in solving clinical problems.

The main objective of this study is to determine if small group case discussions related to upper limb anatomy will improve learning outcomes and increase students' motivation to study anatomy. 


\section{MATERIALS AND METHODS}

All students who took the Gross Anatomy course during the 2012-2013 academic year were required to participate in this project. The study included newly registered students in the first academic year. The total number of students was 165 , and they were divided by alphabetical order into 15 groups of 11 students. Each group was led by one faculty member and each faculty member led three groups, so that there were at least five different leaders for the 15 groups. The role of the leaders during the case discussions was to serve as the domain expert and to facilitate the discussions. The leaders were supervised by the course instructor, and met with the instructor twice a week for 30 min before each group meeting. The students were rewarded for their participation in the case discussion process by including the score of the posttest as part of their final mark of the midterm assessment.

Prior to participation in the case discussions, students completed their study on the anatomy of the upper limb in the traditional mode, which included $3 \mathrm{~h}$ of didactic lectures and $3 \mathrm{~h}$ of dissection lab sessions every week for a period of 6 weeks. Students took a pretest before participating in the case discussions. The process of case study in problem-based learning (PBL) mode was discussed with students. Students in each group had to discuss two different clinical cases. The groups met twice a week for $2 \mathrm{~h}$ each. Each case was discussed in a total of four sessions. There were a total of eight sessions held over a 4-week period. Over four sessions spent discussing each case, the student was asked to use a systematic procedure to analyze the problem, formulate learning objectives, and to collect additional information. The seven steps method of Schmidt ${ }^{[12]}$ was used for this process with slight modification [Table 1]. The specific aims of this method are to foster learning by activating the prior knowledge on the topics to learn, connecting the learning to specific problem situations that might occur in practice, and making the students elaborate on the material that they have learned. Each of the two clinical cases related to the upper limb anatomy contained a patient complaint, past history, and physical examination results. Cases were taken from clinically oriented anatomy ${ }^{[16]}$ with slight modification and translation into Arabic.

$\begin{aligned} & \text { Table I: Combined the seven step method of Schmidt in } \\
& \text { the four sessions }\end{aligned}$
\begin{tabular}{llll}
\hline First session & Second session & Third session & Forth session \\
\hline $\begin{array}{l}\text { Get familiar } \\
\text { with the case }\end{array}$ & $\begin{array}{l}\text { Sketching an } \\
\text { explanatory model }\end{array}$ & $\begin{array}{l}\text { Formulate } \\
\text { learning goals and }\end{array}$ & $\begin{array}{l}\text { Synthesize } \\
\text { and test the }\end{array}$ \\
$\begin{array}{l}\text { materials and } \\
\text { identification }\end{array}$ & $\begin{array}{l}\text { for the problem } \\
\text { and brainstorming }\end{array}$ & $\begin{array}{l}\text { collect additional } \\
\text { information }\end{array}$ & $\begin{array}{l}\text { newly acquired } \\
\text { information }\end{array}$ \\
problem & $\begin{array}{l}\text { to analyze the } \\
\text { problem }\end{array}$ & outside the group & \\
\hline
\end{tabular}

The content of the pre- and posttest consisted of a series of 20 multiple choice questions (MCQs). Each included a clinical vignette and five answer options. At the conclusion of the 4-week case discussion sessions, the students also completed a questionnaire about their opinion of the case study learning process. The questionnaire was in the Likert scale format as strongly agree, agree, no opinion, disagree, and strongly disagree.

The pre- and posttest questions were related to the cases concerning anatomy topics of the upper limb. There was less focus on the direct identification of the structures, more focus on the function and clinical relevance of the anatomy. Care was taken to ensure appropriate distribution of questions from various topics and keeping them relevant to the learning objectives of the course. Each test was graded out of 100 points, with a passing of 60 or above. All questions in both the pre- and posttest were similar. The questions were tested before hand and sorted randomly from the question bank. Students provided their choices on an answer sheet that could be graded by the scanner program used for scoring (Sekonic Optical Mark Reader 3500), using the operating software (Markview Remark Office OMR ${ }^{\odot}$ ). The students had $20 \mathrm{~min}$ to complete each test. The system automatically analyzed the results and provided statistical analysis with the Statistical Package for Social Sciences (SPSS) package software that was included.

\section{RESULTS}

The case discussions included concepts that were related to the most important topics in upper limb anatomy [Table 2].

The pretest score shows that $20 \%$ of the students received grades of $60 \%$ or above and that $80 \%$ received grades less than $60 \%$, The posttest results show that $45 \%$ of the students

\footnotetext{
Table 2: Topics of upper limb anatomy

Bones and Joints, the $\mathrm{X}$-ray of the cervical spine, the $\mathrm{X}$-ray of the shoulder joint, and the $\mathrm{X}$-ray of the elbow and wrist joints

Brachial Plexus: i.e., You are shown a diagram of the brachial plexus with numbered points. You are then shown pictures of patients in various positions. Indicate which points could be injured?

Region of axilla, lymphatic drainage of breast

Course of radial, ulnar and median nerve:Which nerve is damaged by the blood pressure cuff?

Arterial anastmosis around elbow and scapula, palmar Arch

Muscular space of scapular region, brachial and antebrachial region Cubital Fossa: i.e., Identify on patient biceps tendon, brachial artery, and radial nerve. The course of brachial artery in the antecubital fossa. What is the name of aponeurosis in antecubital fossa? Which vein would you choose for a long line on antecubital fossa?

Flexor and extensor retinaculum, intrinsic muscles of hand with nerve supply: Identify positions of radial nerve, ulnar nerve, median nerve, and tendons at the level of flexor retinaculum. What muscles does ulnar nerve supply in the hand?
} 
received grades of $60 \%$ or above and that $55 \%$ received grades less than $60 \%$ [Table 3]. There was a significant differences between the pre- and posttest for grades $\leq 60 \%(P=0.0000)$ and less significant for grades $>60 \%(P=0.0023)$ in comparison between pre-and posttest. In addition, the study reported $17 \%$ of students achieved the same results (less than 60\%) in both the pre- and posttests. Also there was improvement in the high end of the scores on the posttest with $10 \%$ of students scored an 80 or higher on the pretest, while $25 \%$ scored an 80 or above on the posttest.

The opinion questionnaire sheets revealed that the discussion method was useful in their learning process. Case discussions helped them to increase their motivation to study anatomy (85\%), know the usefulness of studying anatomy (84\%), learn how to integrate their knowledge with other subjects (83\%), and understand the problems (91\%) [Table 4].

We applied the case discussion approach after the students had completed their traditional study of the upper limb. The approach we used differs from those based extensively or entirely on PBL. The PBL approach consists of only a few lectures and then the case discussion act as the main stimulus for student learning. ${ }^{[1,12]}$ Such approaches are useful when applied to strongly student-centered educational environments. It is based on the constructivist model in which students construct rather than receive or assimilate knowledge. This model requires active input from students and requires intellectual effort and aids knowledge retention. The role of the teacher in student-centered learning is to facilitate the student's learning by providing a framework to facilitate this learning.

At Al-Baath University Hama, learning experience is mostly teacher-centered. So we feel that a modified version of PBL will work better for our students and can be easily integrated into our curriculum. Haarden ${ }^{[17,18]}$ presented the SPICES model for educational strategies in PBL. He described an

\begin{tabular}{lcc|}
\hline \multicolumn{4}{|l|}{ Table 3: Pre- and posttest results } \\
\hline Max. score: 100 points & Pretest (\%) & Posttest (\%) \\
\hline$>60$ & 80 & 55 \\
$<60$ & 20 & 45 \\
$>80$ & 10 & 25 \\
\hline
\end{tabular}

11 steps-continuum between problem-based learning and information-orientated learning. This continuum offers a practical taxonomy to describe PBL. It emphasizes the range of options and helps to avoid a polarization of viewpoints between enthusiasts and traditionalists. The continuum can also be used as a tool for curriculum evaluation and development. We conclude that the averages for the pre- and posttest are statistically different. The scores appear most distinct in the high score cases. Also there was improvement in the high end of the scores on the posttest, say that $10 \%$ of students scored an 80 or higher on the pretest, but $25 \%$ scored an 80 or above on the posttest. However, $17 \%$ of the students achieved the same results in both the pre- and posttests. The pretest, whereby students' ability to understand questions and answer actively was assessed. The pretest results were poor. This fact was possibly caused by student passivity since they generally take multiple choice tests. The issue of competition for study time between the case studies and the student's other courses. This could be an answer for why some students did not do better on the posttest than the pretest. They may have been too busy studying for other classes and did not feel that the reward for participating in the case studies outweighed their responsibility for performing well in the other courses.

Although the material contained in the case discussions had already been presented during the regular lectures, pre- and posttest answers indicate that case discussion improved students' understanding and application of anatomy knowledge in problem solving.

Research done by Percac and Goodenough ${ }^{[10]}$ showed the same results as ours results. This article describes a Clinical Anatomy course ${ }^{[8]}$ designed to bridge basic anatomy with clinical clerkships. It is given in the $2^{\text {nd }}$ year, after the traditional dissecting anatomy course. Students revisit anatomy during small group discussions of clinical cases. An example of a case is described together with a summary of a typical group process stimulated by the case. The group process enables students to develop clinical thinking and problem solving skills fundamental to clinical practice. They learn to search for medical knowledge resources and to work in teams. The tutor evaluates the students' progress based on their knowledge building, problem solving, and development of their interpersonal skills. PBL

\begin{tabular}{lccccc}
\hline Table 4: Opinion questionnaire results & & & \\
\hline Opinion questionnaire & Strongly agree (\%) & Agree (\%) & No opinion (\%) & Disagree (\%) & Strongly disagree (\%) \\
\hline Increase motivation to learn & 54 & 31 & 6 & 9 & 0 \\
Know the usefulness of study & 40 & 44 & 11 & 5 & 0 \\
Learn to integrate & 60 & 23 & 10 & 7 & 0 \\
Understand the problem & 61 & 30 & 9 & 0 & 0 \\
Useful method in learning & 80 & 20 & 0 & 0 & 0 \\
\hline
\end{tabular}


in this interdisciplinary anatomy course allows students and faculty both horizontal and vertical integration within the curriculum. This approach is comparable to our study by bridging traditional anatomy teaching with case discussion to improve student learning. Scott ${ }^{[9]}$ and Moxham and Moxham ${ }^{[13]}$ also found a meaningful difference when applying case discussion in the traditional medical school. However, students who participated in that research were students who had completed their college education while our students came directly from high schools.

The implementation of PBL increased student motivation to study anatomy, and encouraged our students to develop independent-learning and reasoning skills by introducing case-based studies and help them to become familiar with and committed to the principles of good case discussion, and to answer questions related to patient care. We found out that our students learned that by working in groups, they can train their communication and argumentation skills. They also get support from their peers which helps relieve the anxiety caused by difficult topics. In addition, they learn to search for information from different sources and learn to take more responsibility for their studies. Moreover, the opinion questionnaire results indicated that through case discussion, students were able to recognize the importance of learning anatomy and its relation to other medical disciplines. Case discussion also seems to be more interesting to the students compared with the traditional teaching/learning process, as they were challenged with "real clinical problems". All students suggested that this method should be carried out in anatomy teaching along with more cases. This outcome appears to be in line with the opinions and observations of educational experts elsewhere. ${ }^{[3,11,12,19]}$

Different teaching strategies can be applied simultaneously to teach anatomy to large groups of students. As a matter of fact it is important to use multiple techniques in order to reach as many different types of learners as possible. In our experience at the Al-Baath University, teaching anatomy to large cohorts (greater than 200) has been challenging using the traditional transmission technique (i.e., lecture). Therefore, developing an effective delivery method of course material was necessary.

Both students and professors agreed that use of dissection and/or prosection were the most efficient teaching method. Kerby et al., ${ }^{[20]}$ listed other teaching methods that were ranked by professors and students. These methods include: Living people/radiology, computer assisted learning, didactic, and lastly models. This ranking showed that lecture are not necessarily the most effective way to teach anatomy, and that both teachers and students prefer other methods. This ranking is related to our study by using the same methods of teaching anatomy during lecture and case discussion sessions. That is why we suggest that a multimodality approach should be used. ${ }^{[1,4,14,15]}$

\section{CONCLUSION}

As a student-centered philosophy of education, the implementation of the case discussion approach in teaching the anatomy subject can increase the students' understanding of the subject as well as motivate them to learn. Multiple modality approach and using multimedia may also be an effective teaching strategy. This allows the students to actively participate in the curriculum process of learning, removes the traditional student/teacher barrier and encourages more student-to-student interaction.

\section{ACKNOWLEDGMENTS}

To all the students who had participated in giving their feedback, all the panel examiners who had helped in the design, conduct, and administration of the tests and questionnaires and those who had given their invaluable advice and comments during the project.

\section{REFERENCES}

1. Brenton H, Hernandez J, Bello F, Strutton P, Purkayastha S, Firth T, et al. Using multimedia and Web3D to enhance anatomy teaching. Comput Educ 2007;49:32-53.

2. Gabard DL, Lowe DL, Chang JW. Current and future instructional methods and influencing factors in anatomy instruction in physical therapy and medical schools in the U.S. J Allied Health 2012;41:53-62.

3. Klement BJ, Paulsen DF, Wineski LE. Anatomy as the backbone of an integrated first year medical curriculum: Design and implementation. Anat Sci Educ 2011;4:157-69.

4. Pallab KG, Lap KC. Living anatomy in the $21^{\text {st }}$ century: How far can we go? Southeast Asian J Med Educ 2008;2:52-7.

5. Bergman EM, van der Vleuten CP, Scherpbier AJ. Why don't they know enough about anatomy? Med Teach 2011;33:403-9.

6. Peplow PV. Self-directed learning in anatomy: Incorporation of case-based studies into a conventional medical curriculum. Med Educ 1990;24:426-32.

7. Pabst R. Gross anatomy: An outdated subject or an essential part of a modern medical curriculum? Results of a questionnaire circulated to final-year medical students. Anat Rec 1993;237:431-3.

8. Moxham BJ, Shaw H, Crowson R, Plaisant O. The future of clinical anatomy. Eur J Anat 2011;15:29-46.

9. Scott TM. A case-based anatomy course. Med Educ 1994;28:68-73.

10. Percac S, Goodenough DA. Problem-based teaching and learning as a bridge from basic anatomy to clinical clerkships. Surg Radiol Anat 1998;20:203-7.

11. Barrows HS, Tamblyn RM. Problem-based learning. An approach to Medical Education. New York: Springer Publishing Company; 1980.

12. Schmidt HG. The rationale behind problem-based learning. In: Schmidt HG, Lipkin M de Vries, Greep JM, editors. New Directions for Medical Education. Problem-Based Learning and Community-Oriented Medical Education. Berlin: Springer-Verlag; 1989.

13. Moxham BJ, Moxham SA. The relationships between attitudes, course aims and teaching methods for the teaching of gross anatomy in the medical curriculum. Eur J Anat 2007;11:19-30. 
14. Pereira JA, Merí A, Molina-Ros A, Molina-Andreu O. Web-based course for teaching human anatomy The UPF experience. Eur J Anat 2003;7:19-22.

15. Edgell $\mathrm{H}$. Teaching anatomy with multiple techniques, teaching innovation projects 2011;1. 1, Article 3.

16. Moore KL. Clinically oriented anatomy. Baltimore: Williams and Wilkins; 1985.

17. Haarden RM, Sowden S, Dunn WR. Some educational strategies in curriculum development: The SPICES model. Med Educ 1984;18:284-97.

18. Haarden RM, Davis MH. The continuum of problem-based learning. Med Teach 1998;20:317-22.
19. Bouhuijs PA, Schmidt HG, van Berkel. Problem based learning as an educational strategy. Malta: Network Publications; 1993.

20. Kerby J, Shukur ZN, Shalhoub J. The relationships between learning outcomes and methods of teaching anatomy as perceived by medical students. Clin Anat 2011;24:489-97.

Cite this article as: Sabbagh MA. Application of case discussions to improve anatomy learning in Syria. Avicenna J Med 2013;3:87-91.

Source of Support: Nil, Conflict of Interest: None declared.

\section{“QUICK RESPONSE CODE” LINK FOR FULL TEXT ARTICLES}

The journal issue has a unique new feature for reaching to the journal's website without typing a single letter. Each article on its first page has a "Quick Response Code". Using any mobile or other hand-held device with camera and GPRS/other internet source, one can reach to the full text of that particular article on the journal's website. Start a QR-code reading software (see list of free applications from http://tinyurl.com/yzlh2tc) and point the camera to the QR-code printed in the journal. It will automatically take you to the HTML full text of that article. One can also use a desktop or laptop with web camera for similar functionality. See http://tinyurl.com/2bw7fn3 or http://tinyurl.com/3ysr3me for the free applications. 